\title{
Effect of Pre-Stretching on Microstructures and Mechanical Behaviors of Creep-Aged 7055 Al Alloy and Its Constitutive Modeling
}

\author{
Duquan Zuo ${ }^{1,2, *}$, Zengqiang Cao ${ }^{1, * \mathbb{C}}$, Yuejie Cao ${ }^{1}$ and Guo Zheng ${ }^{1}$ \\ 1 School of Mechanical Engineering, Northwestern Polytechnical University, Xi'an 710072, China; \\ cyj264950@mail.nwpu.edu.cn (Y.C.); Zhengguo@mail.nwpu.edu.cn (G.Z.) \\ 2 Chongqing Engineering Technology Research Center for Light Alloy Materials and Processing, \\ Chongqing Three Gorges University, Chongqing 404100, China \\ * Correspondence: taiyanghefeng@mail.nwpu.edu.cn (D.Z.); czq66326@nwpu.edu.cn (Z.C.); \\ Tel.: +86-023-5810-5722 (D.Z.); Tel.: +86-029-8849-4454 (Z.C.)
}

Received: 30 April 2019; Accepted: 17 May 2019; Published: 21 May 2019

\begin{abstract}
The rational pre-stretching can contribute to obtaining better mechanical properties. This paper studies the effect of creep stain, mechanical properties, and microstructures of 7055 alloy under different pre-stretching conditions. The results show that compared with solid-quenched alloy, the 7055-T6 alloy is the optimal scheme to attain more creep strain, and the range of pre-stretching from $1.6 \%$ to $3.3 \%$ is suitable for creep-aged 7055-T6 alloy to obtain better mechanical properties. Further examination by TEM test shows that pre-stretching promotes the formation of dislocations, which provides superior nucleation regions for $\eta$ phase resulting in a higher strength alloy. Meanwhile, a unified creep-aging constitutive model for 7055-T6 alloy is established which can be used to accurately predict its creep behavior under the different pre-stretching.
\end{abstract}

Keywords: 7055 alloy; pre-stretching; creep-aging; mechanical behaviors; microstructures; constitutive model

\section{Introduction}

Aluminum alloy 7055, as a kind of Al-Zn-Mg-Cu alloy with higher alloy forming properties, exhibits better comprehensive performance such as high-strength, high-toughness, strong propagation ability of anti-fatigue crack, and good fracture toughness, is widely used in aeronautical structures such as aircraft wings [1]. It is through solid solution, homogenization, pre-stretched deformation, and thermo-mechanical treatment that 7055 alloy with the comprehensive characteristics of high strength, high toughness and strong corrosion resistance, can be obtained. In recent decades, the effects of the methods mentioned above on microstructures and mechanical behaviors of alloys have been developed by many studies [2-4]. For dealing with spray forming of 7055 AA, Schreiber et al. [2] demonstrated that it was feasible to improve its mechanical properties using the composited methods of extrusion and heat treatment. Rodgers et al. [3] investigated the influence of larger pre-stretching on mechanism properties of aged AA2195 alloy, and it was shown that, within such high pre-strains, the strengthening from $\mathrm{T}$ phase will be reduced, and the strain hardening would be increased due to precipitate refinement. Cao et al. [4] found that the response of aged hardening for Al-Mg-Cu-Zn alloy would be obviously improved with the pre-aging treatment because of the existence of high density of finer and equiaxed $T$ phases, with the annihilation of $S$ phases.

According to the above research results, the pre-stretching treatment before aging can form pre-stress and pre-strain, and it contributes to raising the dislocation density in alloys, decreasing the size of precipitated phase particles, and shortening the time of peak ageing. In actual industrial treatment, the above heat aging process and applied strain field or external stress field, is used as a very 
significant method to improve the mechanical performance of metals [5]. However, the combined treatment of both the creep aging and the pre-stretching is an efficient mechanism to promote the forming capabilities, retain the forming shape and enhance the mechanical properties of alloys. Although many studies have focused on creep aging forming (CAF) and pre-stretching, as standalone processes $[3,4,6,7]$, only a few reports have focused on the combined processes of both the pre-stretching and CAF and its constitutive model with per-strain, especially on the creep characterization of creep aging tensile process.

CAF takes full advantage of the age hardening feature and creep behavior of metals that can meet the demands of manufacturing large integral panels with both the better shape and performance [8]. However, precise regulations of both deformed shape and material properties are very difficult due to the strong interactions between dislocations deriving from pre-strain and creep behavior in the CAF process. In this way, the influence of pre-straining level on the change in creep deformation and failure of $316 \mathrm{H}$ stainless steel has been investigated [9]. This resulted in the conclusion that the introduced pre-strains can promote creep ductility and decrease rupture times of the studied material. A CAF experiment on 2219 sheet specimens under different pre-deformation conditions have already been conducted [10], and its results show that the introduction of pre-deformation can significantly improve forming qualities of creep ageing specimens, in turn, reducing their spring-back. Further, the constitutive model, as a key step before the study on CAF, can be accurately used to describe creep behavior of materials [11,12].

Thus, there is a huge scientific research value and engineering application significance to present the effect of mechanical properties and microstructures of creep-aged 7055 alloy under different pre-stretching conditions and its creep constitutive model with the pre-stretching conditions. In this work, for Al 7055 alloy, the design and planning of the entire experimental programme was first introduced. This included a scheme comparing the solution-quenching treatment and the T6 treatment before creep-aging. Secondly, the influence of microstructures and mechanical performances of creep-aged 7055-T6 alloy under the different pre-stretching conditions and its creep behaviors were revealed from the analysis of creep tensile test results. Lastly, a set of unified creep aged constitutive model with pre-stretching was presented. This could describe well, the aging mechanism and mechanical properties evolution of Al 7055 alloy. The parameters in constitutive equation were also determined. This work was beneficial in choosing a reasonable range of pre-stretching, manufacture satisfying 7055 alloy materials and in promoting the wide application of the studied alloy.

\section{Experimental Programme}

\subsection{Test Materials}

The commercial materials, Al 7055, of nominal chemical composition (given in Table 1), used in the creep tests, were provided by an aeronautical manufacturing enterprise as hot-rolled plates. Creep specimens with a gauge length of $30 \mathrm{~mm}$ were machined from plates of $1.5 \mathrm{~mm}$ thickness along its rolling direction, X (longitudinal direction, LD), according to the ISO 204-2009 (Metallic materials-Uniaxial creep testing in tension-Method of test, MOD) standard, and the main dimensions of the remainder were: $90 \mathrm{~mm}$ in length, and $22 \mathrm{~mm}$ in width (see Figure 1).

Table 1. Chemical composition of Al 7055 alloy, (mass fraction, \%).

\begin{tabular}{cccccccccc}
\hline $\mathbf{Z n}$ & $\mathbf{M g}$ & $\mathbf{C u}$ & $\mathbf{Z r}$ & $\mathbf{F e}$ & $\mathbf{M n}$ & $\mathbf{S i}$ & $\mathbf{T i}$ & $\mathbf{C r}$ & $\mathrm{Al}$ \\
\hline 7.9 & 2.1 & 2.3 & 0.05 & 0.15 & 0.05 & 0.1 & 0.06 & 0.001 & Bal. \\
\hline
\end{tabular}




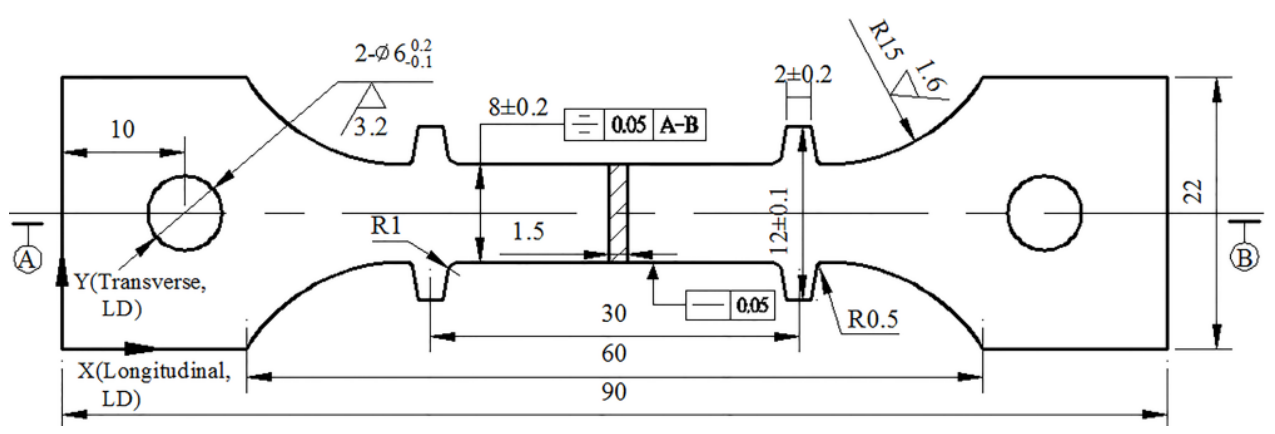

Figure 1. Specimens used for tensile tests in creep aging (unit: $\mathrm{mm}$ ).

\subsection{The Overall Test Programme and Microstructure Description}

Three groups correspond to three kinds of experimental schemes (signed by (1), (2) and (3)). One is an Al 7055 plate treated with solid solution and the other two are Al 7055 plates treated with T6, with or without pre-stretching treatment. These were creep-tested to investigate their properties of creep-ageing. The samples prepared in scheme (1) (see the blue line of Figure 2) were held at $470{ }^{\circ} \mathrm{C}$ for $1 \mathrm{~h}$ in the vacuum resistance furnace and then the specimens were immediately quenched in ambient temperature water. Meanwhile, some samples among them that respectively corresponded to schemes (2) and (3) were designed to be held at $120^{\circ} \mathrm{C}$ for $24 \mathrm{~h}$ in the drying oven during $\mathrm{T} 6$ treatment (see the red line of Figure 2) and then part of the samples were still subjected to pre-stretching treatment (see the green line of Figure 2). Next, the creep-aging tests were conducted on all of samples under stress range (e.g., 150 to $240 \mathrm{MPa}$ ) for a controlled amount of time (e.g., $12 \mathrm{~h}$ ) at $155{ }^{\circ} \mathrm{C}$. Finally, the tensile tests were further conducted at room temperature with a constant speed of $3 \mathrm{~mm} / \mathrm{min}$.

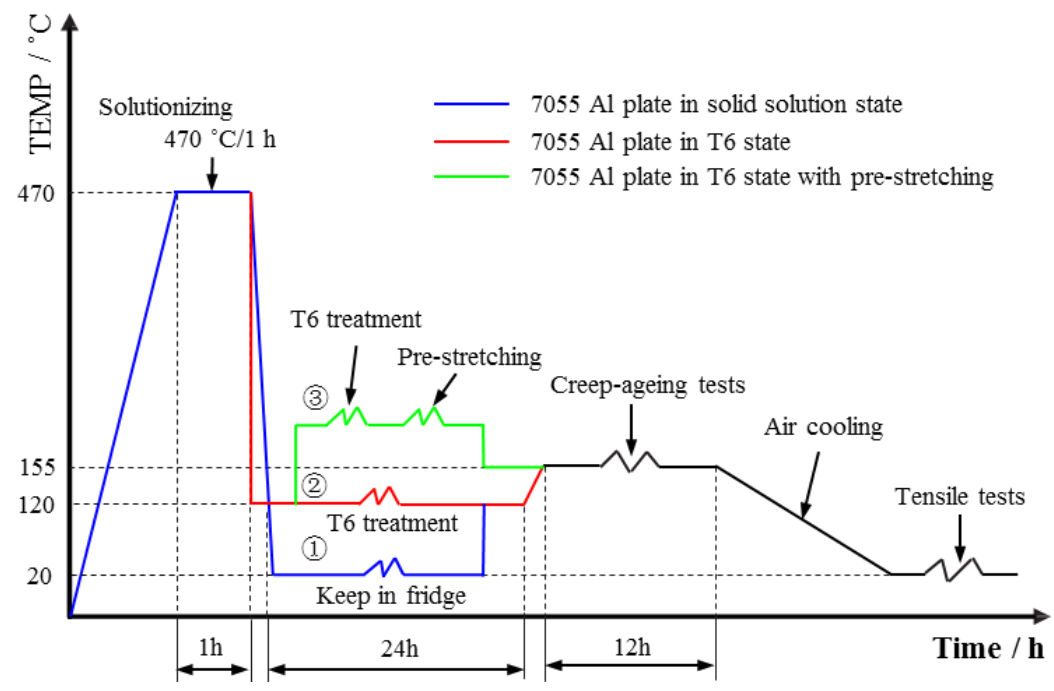

Figure 2. Material preparation, scheme chosen, and overall test programme presenting corresponding optimal scheme.

The above-mentioned pre-stretching was planned to be conducted under the strain scope of $0 \%$ through 7\% along LD of specimens experienced to T6 state on 300 Series TESTRESOURCES' Universal Test machine (TestResources Inc., Shakopee, MN, USA) at room temperature with a constant speed of $1 \mathrm{~mm} / \mathrm{min}$, and the creep-aging tests were performed on RDL 50 Electronic Creep Testing machine (Changchun Research Institute for Mechanical Science Co., Ltd, Jilin, China). The experimental procedures of creep-aging for 7055 in T6 state could be described, as follows:

- First of all, the pre-stretched specimen was fixed and aligned in the middle of the furnace, and three thermocouples were respectively wired in the middle and two ends of the specimen gauge length. 
- Next, the furnace door was closed, the top and bottom of furnace were covered using thermal cotton and was heated until the temperature rose and reached a steady $155^{\circ} \mathrm{C}$ before the extensometers were calibrated and the load was applied. The elongation of the specimen was measured every $0.5 \mathrm{~h}$ by the data logger.

- Finally, when the creep time reached $12 \mathrm{~h}$, heating switch was turned off, then the furnace door was opened and the load was removed.

The creep-aging tests using the above-mentioned experimental steps were repeated for actual pre-stretching levels, e.g., $0 \%, 1.6 \%, 3.3 \%, 5.0 \%$, and $6.7 \%$, when the actual stresses corresponding to pre-strains were $0 \mathrm{MPa}$, $94.8 \mathrm{MPa}, 393.8 \mathrm{MPa}$, $547.3 \mathrm{MPa}$, and $564.5 \mathrm{MPa}$, respectively. The mechanical properties (e.g., yield strength, the ultimate tensile strength, and/or the elongation at break) of specimens treated by the pre-stretching before or after the creep-aging process were measured. Next, their thin foils for TEM observation were cut with a low-speed saw and machined down to $50 \mathrm{um}$ in thickness. The foils were then punched into discs of $3 \mathrm{~mm}$-radius. This was followed by standard twin-jet-electro-polishing using a solution of $30 \%$ nitric acid in methanol as the electrolyte, maintained at a temperature of $-20^{\circ} \mathrm{C}$ and a potential difference of 15 V. JEM-2000CX TEM (Japan Electron Optics Laboratory, Kowloon, HK) operating at $200 \mathrm{KV}$ was used to observe the structural morphologies of the above alloy materials.

\section{Experimental Results and Discussion}

\subsection{Effect of Heat Treatment State on Creep Behaviors for 7055 Alloy}

Figure 3 depicts the creep strain curves of 7055 alloy plates in both solid solution state and T6 state at temperature of $155^{\circ} \mathrm{C}$ under different stress levels, for $12 \mathrm{~h}$. For 7055 alloys in solid solution state in Figure $3 \mathrm{a}$, it is worth noting that all creep-strain profiles show an increasing trend with the increase in stress. The creep rate is generally thought as having a complicated relationship with the applied stress. The lower the stress condition is, the smaller the creep rate is in the first stage (named as transient creep period), but the longer the creep duration is in the second stage (called steady-state creep period). Then the creep curves enter into the third stage in around $4.25 \mathrm{~h}$ (separated by the orange dotted line, known an accelerated creep period), and creep strain of this stage only accelerates to a maximum of $0.09 \%$. This indicates that the creep aging performance of 7055 plate in solid solution state is extremely inferior, which cannot be used in the later experimental tests. The reason is that, to satisfy the actual production, relatively higher stress level should be selected so as to obtain more creep strain without reducing its mechanical properties [12].
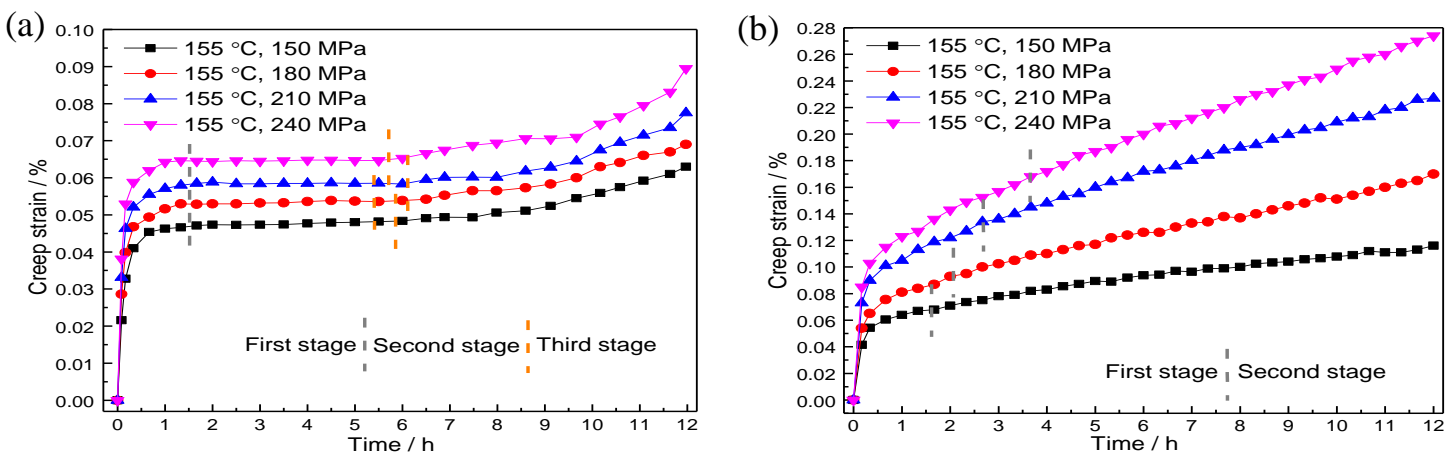

Figure 3. Comparisons of profiles for experimental creep strains of $7055 \mathrm{Al}$ plate (a) in solid solution state and (b) in T6 state for $12 \mathrm{~h}$ under applied stress levels: $150 \mathrm{MPa}, 180 \mathrm{MPa}, 210 \mathrm{MPa}$, and $240 \mathrm{MPa}$.

Therefore, the creep tensile behaviors of the specimens experienced by T6 are further investigated (see Figure 3b). Under the circumstances, the 7055 alloys subjected to treatment by T6 exhibit typical features of the former two stages of creep (divided by the gray dotted line of Figure 3b) [13]. It may be noted that the materials treated by T6 have greater creep strain than that of solution-quenched 
counterparts. The reasons for this involve the greater creep strain in first stage and also the longer duration for the creep rate during second stage. For instance, for the sample signed by pink line, the maximal strain shown in Figure $3 b$ in the primary creep stage is significantly larger than that shown in Figure $3 a$ (note that the creep strain of the former is 3 times more than that of the latter in terms of detail). Then, the creep curves of solution-quenched specimens enter into the second stage (separated by the gray dotted line) and the maximum creep strain accumulating at that period is up to $0.065 \%$ (see the pink line of Figure 3a) after $1.5 \mathrm{~h}$ of ageing. But it only takes $3.5 \mathrm{~h}$ for samples treated by $\mathrm{T} 6$ to reach the maximum $-0.165 \%$ of creep strain in the same stage. This shows that compared with solid-quenched treatment, the effect of T6-treated 7055 alloy is extremely beneficial because the creep strain of the first stage generates more and creep time of the second stage lasts longer. The maximum duration of Figure 3a,b in second stage are $4.25 \mathrm{~h}$ and $10.4 \mathrm{~h}$, respectively, and the duration of the latter is 2.4 times than that of the former. Then, the maximal amount of creep strain in the third stage of Figure 3a seen in pink line accumulates up to $0.09 \%$, but it is in the steady-state creep stage that maximum creep strain of $0.274 \%$ has been achieved (as shown the pink line of Figure 3b). This phenomenon can also be used to demonstrate the fact that 7055 alloy treated by T6 has positive effects on the produce of creep strain. In a word, compared with the solution-quenched alloy plate, the 7055-T6 alloy shows better secondary creep after being loaded within a short duration of primary creep.

\subsection{Effect of Pre-Stretching on the Creep and Mechanical Properties for 7055-T6 Alloy}

From the current study, it can be seen that the 7055-T6 alloy exhibits the characteristics of high creep strain. In order to make the studied alloy meet the performance requirements better to be applied to aircrafts (e.g., fuselage, wings and other components) [14], the T6-treated specimens before creep-ageing, as an optimal scheme compared to solution-heated treatment, were further selected to conduct pre-stretching to explore its effect on the alloy.

The true stress-strain curves for the studied 7055-T6 alloy under different pre-stretching conditions at atmospheric temperature are shown in Figure $4 \mathrm{a}$. The corresponding mechanical properties including the tensile strength, yield strength and elongation are presented in Figure $4 \mathrm{~b}$. The initial tensile and yield strengths of 7055-T6 are immediately measured after pre-stretching while it is about 509.35 MPa and 411.42 $\mathrm{MPa}$ for the un-stretched specimens, respectively. And the strengths of pre-stretched samples of $6.7 \%$ increase significantly to $540.76 \mathrm{MPa}$ and $463.52 \mathrm{MPa}$, respectively. It can be seen clearly that the mechanical behaviors of material treated by T6 are tremendously influenced by pure pre-stretching treatment at room temperature. This reason can be ascribed to work-hardening effect, with greater pre-stretching, resulting in higher tensile and yield strengths of the studied alloy before creep-aging process, where the strengths show significantly monotonous trend.

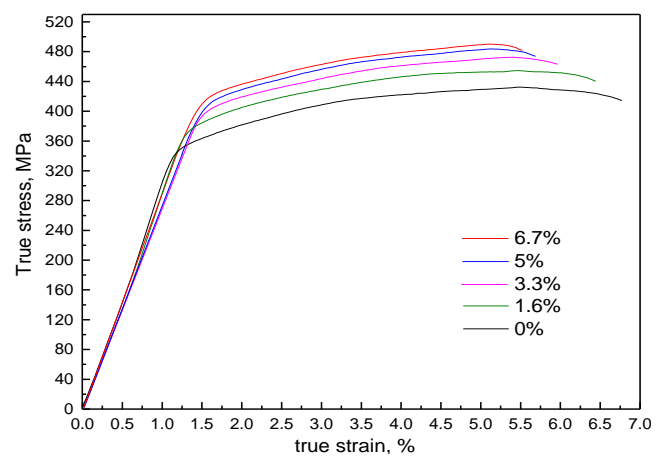

(a)

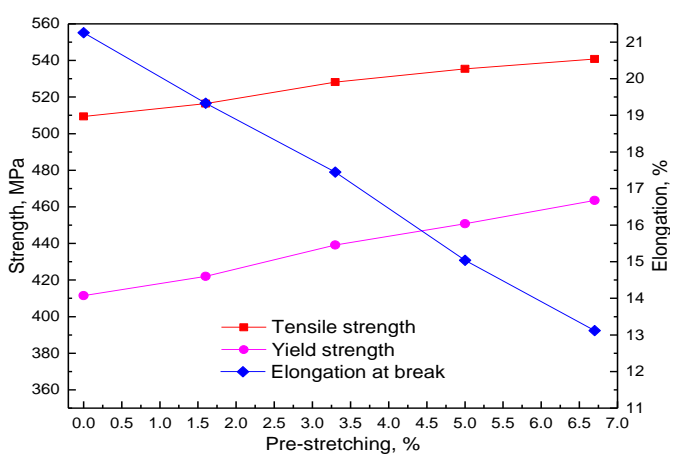

(b)

Figure 4. Profiles of (a) the true stress-strain for 7055 in T6 state alloys with different levels of pre-stretching at room temperature, and (b) variations of mechanical properties for the 7055 in T6 state alloys with different levels pre-stretching before creep-aging. 
The curves of yield strength, the tensile strength and the pre-stretching after creep-aging are presented in Figure 5a. Among them, the corresponding pre-stretching treatments are performed along LD $(X)$ of 7055-T6 plates. It can be clearly seen that the mechanical properties of 7055-T6 alloy without pre-stretching but with creep aging are: yield strength of $474.8 \mathrm{MPa}$ and tensile strength of 545.9 MPa. Compared with the pre-stretched 7055-T6 alloy without creep-aging (see Figure 4b), the introduced pre-stretching can be concluded to be helpful for further improving the strengths of the creep-aged alloy (see Figure 5a). For a detailed explanation, both the tensile and yield strengths of the investigated alloy show a tendency to slow increase at first and then quick decrease with the increase of pre-stretching, where the corresponding maximum levels are $554.43 \mathrm{MPa}$ (corresponding to pre-stretching of $1.6 \%$ ) and $495.1 \mathrm{MPa}$ (corresponding to pre-stretching of 3.3\%), respectively.

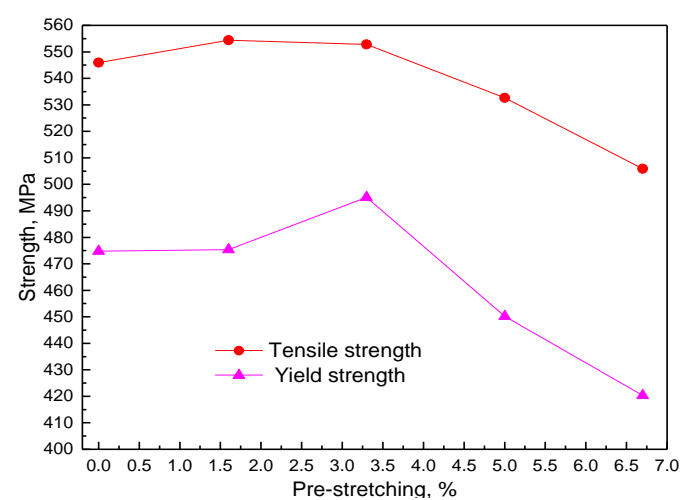

(a)

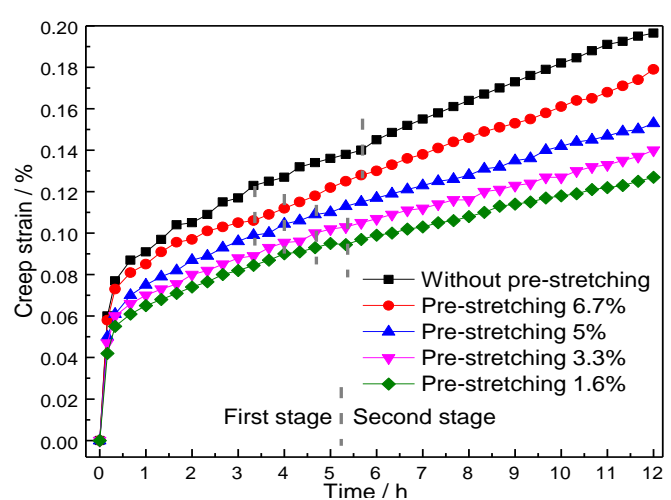

(b)

Figure 5. Variations of (a) tensile strength and yield strength against pre-stretching after creep-aging, and comparisons of $(\mathbf{b})$ creep strain curves between pre- and non-stretched 7055-T6 alloys at $155{ }^{\circ} \mathrm{C}$ with a stress level of $190 \mathrm{MPa}$.

From the above-discussed change in regulation, we can see that the strength of alloy fluctuates little when the change in strength is less than the critical pre-stretching value of $3.3 \%$. On the contrary, great fluctuations in strength appear for that of alloy. Thereby when the range of pre-stretching deformation is from $1.6 \%$ to $3.3 \%$, the performance of alloy is relatively stable. Therefore, compared with un-stretched 7055-T6 alloy in Figure 4b, it can be concluded that creep-aging can change and balance the strength properties of monotonically increasing for the studied alloy and significantly strengthen material resulting in improving its own strength greatly.

Figure $5 \mathrm{~b}$ presents the comparisons of creep strain curves between pre- and un-stretched 7055-T6 alloy under $155^{\circ} \mathrm{C}$ and $190 \mathrm{MPa}$ but different degrees of pre-stretching. It can be clearly seen that the creep strain increases with the degree of intensity of pre-stretching at a certain time and all of the creep strain curves increase with the extension of aging time. Further analysis indicates that a $70 \%$ increase of the total creep strain for non-stretched specimen originates from the primary creep stage but creep strain of those with pre-stretching is smaller. This may be explained from the fact that the degree of pre-stretching can distinctly decrease the duration of the first stage and indirectly enhance the creep rate in steady-state creep stage. Overall, larger pre-stretching will promote the positive effects on creep behaviors, resulting in the generation of more creep strain. The basis that creep strain rates of all specimens treated by pre-stretching in the first stage are lower than that of un-stretched sample can be explained by two facts. One is that the pre-stretching treatment introduces many kinds of defects such as dislocations and vacancies in the matrix [15], which act as strong obstacles to the dislocation movements, leading to the precipitation of the second phase. Meanwhile, the work hardening caused by the pre-stretching facilitates the accumulation of internal dislocation resulting in the generation of creep strain is hindered by more deposits [16]. The other one is that in the steady-state creep stage, the dislocation slip and the climb are easier to occur due to the existence of abundant dislocations, thus contributing to the rise of second stage creep rate. 


\subsection{Effect of Pre-Stretching on Microstructures on 7055 Alloy}

In this section, we will present the microstructures of the solution treated, T6 treated (and then pre-stretched) 7055 alloys and the microstructure evolution that occurs in creep-aging of the pre-stretched 7055-T6 alloys. Figure 6a,b show the TEM micrographs of the un-stretched alloys with states treated by the solutionizing and T6 treating before the creep-aging process. Almost no precipitates in the matrix (see Figure 6a) are detected and a majority of the precipitates in alloy, treated by T6 (see Figure 6b), are very tiny and distributed uniformly, with sizes ranging from 1.8 to $6.2 \mathrm{~nm}$. Generally, the formation of numerous vacancies for alloys treated by the solid solution will condense due to super-saturation after water quenching treatment or T6, and then collapse to develop dislocations [17]. Nevertheless, the number of these dislocations is tiny and easy to reduce at atmospheric temperature. As a result, the dislocations in solid solution alloy and in T6-teated alloy are not detected as shown in Figure $6 \mathrm{a}, \mathrm{b}$. However, it can be observed clearly from Figure 3c,d that a large number of dislocations appear in the T6-treated alloy due to the pre-stretching. This happens on the account of stress concentrating in the local region. With the extension of pre-stretching, the dislocation densities increase.

Figure 7 shows TEM micrographs recorded near the $<011>$ incident beam and the corresponding selected area electron diffraction (SAED) patterns recorded parallel to $<011>$ Al zone axes of pre-stretched alloys after creep-aging at $155^{\circ} \mathrm{C}$ and $190 \mathrm{MPa}$ for $12 \mathrm{~h}$. From Figure $7 \mathrm{a}$, we can easily see that a few dislocations are detected in creep-aged specimen with the pre-stretching of $0 \%$. This can be explained by the fact that these dislocations are affected by the creep strain at the first creep stage. It is generally regarded that, in 7055 alloy, the release sequence of precipitation phase follows successively from $\alpha$ (supersaturated solid solution), GP zone, $\eta$ phase $\left(\mathrm{MgZn}_{2}\right)$ and $\eta$ phase $\left(\mathrm{MgZn}_{2}\right)$. The discoid or rod-like $\eta$ phase is the metastable phase, which is the main source that contributes to strengthening of aluminum matrix. However, the plate-like $\eta$ phase is the equilibrium phase, which will be a sign of the decrease of strength in the alloy when $\eta$ phase is dominant [18]. As shown in Figure 7a, the detectable precipitate in alloy can be identified as $\eta$ phase by consulting the model in some references $[19,20]$, and the corresponding SAED pattern also reveals that there is $\eta$ phase in this un-stretched specimen creep-aged for $12 \mathrm{~h}$.
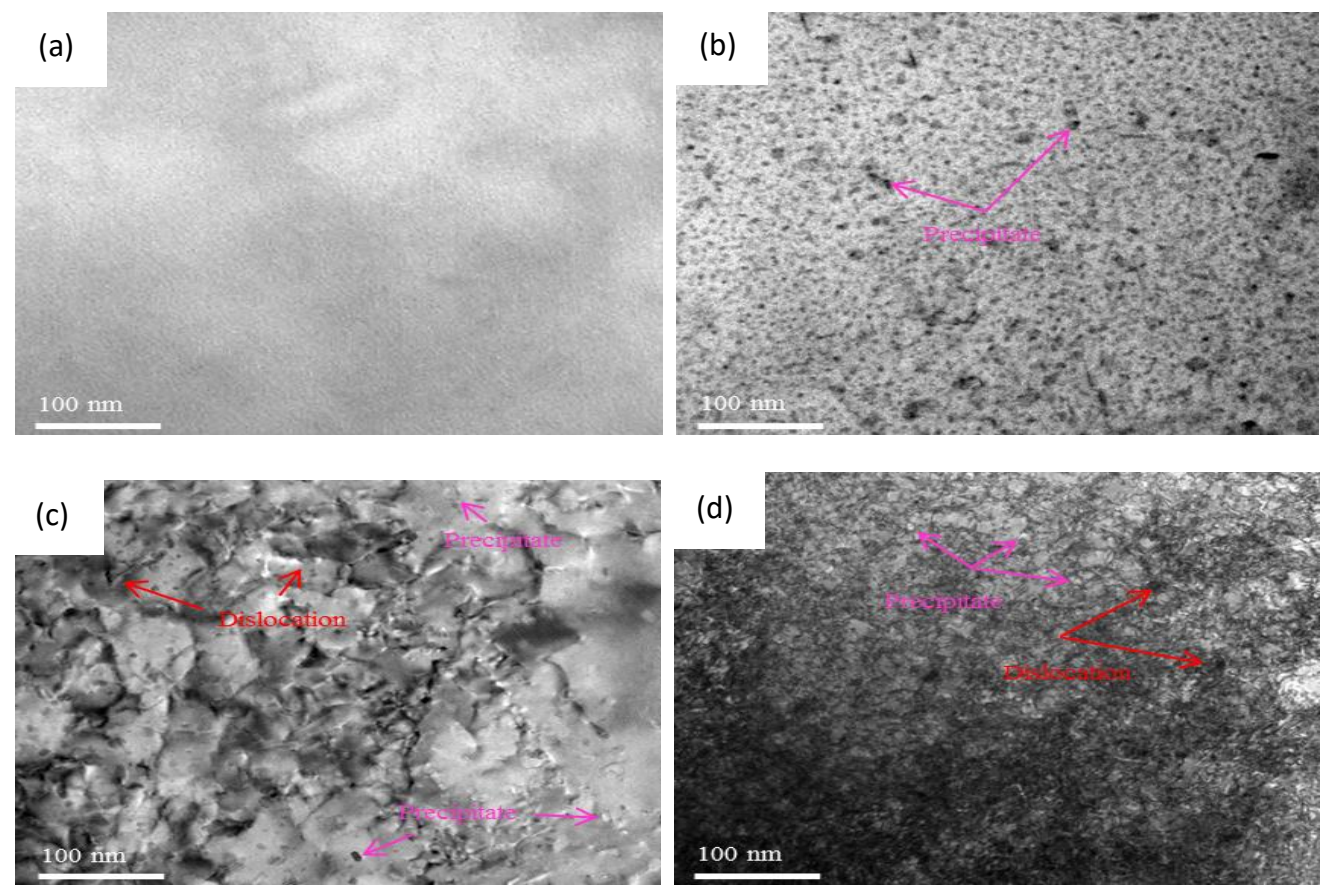

Figure 6. Initial microstructures of the un-stretched alloys with different states of (a) solutionizing; (b) T6; and TEM micrographs of the alloys treated by T6 before conducting creep-aging tests with various pre-stretching conditions of (c) $1.7 \%$ and (d) $6.7 \%$. 
Besides, compared with pure pre-stretched 7055-T6 alloys (Figure 6c,d), it can be clearly seen from Figure $7 b, c$ that lots of dislocations such as dislocation loops and tangled dislocations in the matrix are formed after the applied creep-aging occurs. These dislocations contribute to enhancing the mechanical properties of the studied alloy (see Figure 5a) and promote the transformation of creep strain during creep-aging process (see Figure $5 b$ ). This phenomenon can be explained in more detail from the process where the numerous dislocations in the form of entanglement or loop are dragged into the aluminum matrix due to pre-stretching before creep-aging. The existence of deficiencies provide superior nucleation region for $\eta$ phase, and then promote their finer dispersion. Meanwhile, the dislocations induced during creep-aging process originate from the dilapidation of vacancies. The excess vacancies can increase the diffusion rate of precipitated phase in alloy and accelerate the precipitating behavior and uniform distribution of $\eta$ phase resulting in better strength. In addition, the increase of strength in pre-stretched alloy after creep-aging is ascribed to the dislocations inducing work-hardening effect on the studied alloy in the primary creep stage.

(a)

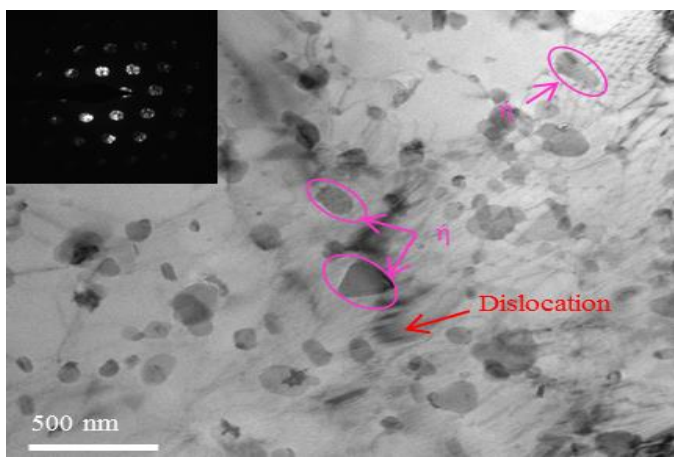

(c)
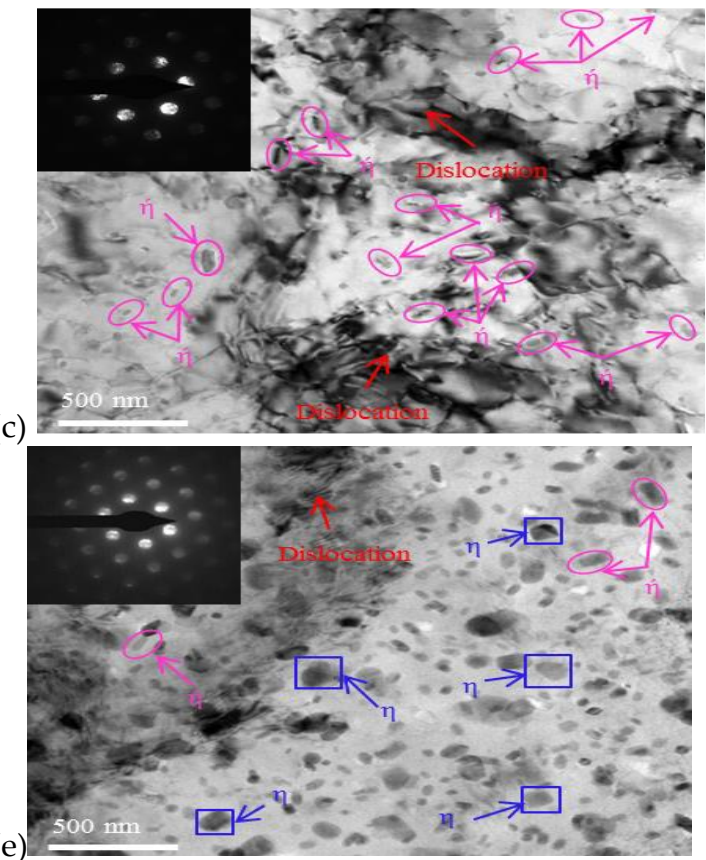

(b)

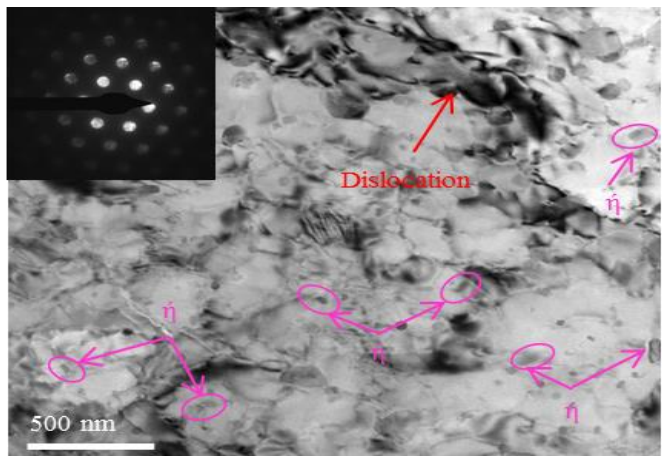

(d)

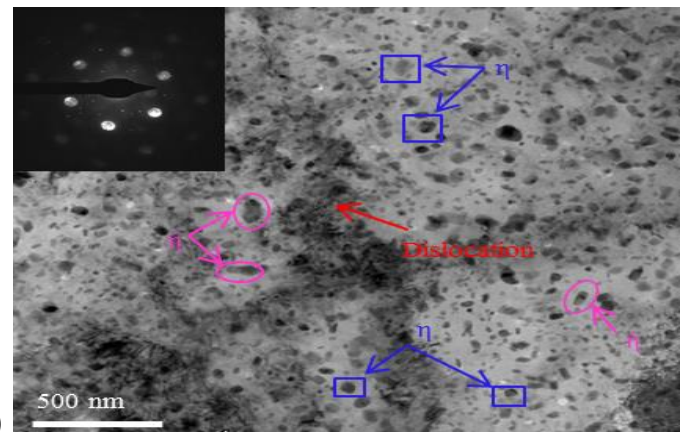

Figure 7. Bright field TEM images showing the microstructures of the pre-stretched 7055-T6 after the creep-aging tests, under various pre-stretching conditions (a) $0 \%$, (b) $1.7 \%$, (c) $3.3 \%$, (d) $5 \%$, and (e) $6.7 \%$.

For pre-stretched alloys under the conditions 5\% and 6.7\% (see Figure $7 d, e$ ), $\eta$ phase and $\eta$ phase can be observed in grains. However, it is obviously different for the different quantities and distributions of these precipitated phases due to the degree of pre-stretching. With the increase of pre-stretching amount, compared with that in Figure 7d, there is more number of and coarser $\eta$ phases distributing dispersively in grains (see Figure 7e), however, it is little by little that $\eta$ phase diminishes 
and nearly vanishes. This is due to the fact that the demand of volume free energy to form $\eta$ phase (as an equilibrium phase) is greater than that of $\eta$ phase (as a metastable phase) [21]. Meanwhile, the trap for vacancies annihilation may be caused by the dislocations generated by pre-stretching, with a decrease of vacancy amount. Thus, the precipitation abilities of $\eta$ phase are obviously weakened. This result is the decreased strength of the studied alloy.

Based on the results discussed-above, the numerous dislocations produced by pre-stretching in aluminum matrix have a more positive effect on $\eta$ phase than $\eta$ phase and make them distribute more dispersively. Otherwise, it has a negative effect on the precipitation and distribution of $\eta$ phase. These also respond to the previous results that the range of pre-stretching from $1.6 \%$ to $3.3 \%$ is suitable for creep-aged alloy to obtain better mechanical properties. Otherwise, the excess pre-deformation brings more $\eta$ phase into the matrix after creep-aging, which leads to the reduction of alloy strength.

\section{Unified Creep-Aging Constitutive Model with Pre-Stretching}

\subsection{Establishment of Material Model}

The creep behavior of aluminum alloys is very complicated and is usually accompanied by the combination changes such as creep strain, stress relaxation and micro-structure state, and so on. The effect of pre-stretching on alloy plates originates mainly from microstructure evolution, such as dislocation motion, grain growth, grain boundary slip, and second-phase precipitation, and the diffusion mechanism which are mainly induced by dislocation, precipitates and solute-matrix bonding [22]. For convenience in engineering application, Kowalewski et al. [23] have proposed a unified creep damage model which can reflect the creep behaviors from the primary creep stage to the accelerated creep stage.

However, in the terms of the studied 7055-T6 alloy with pre-stretching, the short-term aging time in the process of CAF prevents the creep behavior for tertiary stage of the material from occurring. Therefore, the present work establishes a simplified model that can describe the creep behaviors of the former two stages in creep instead of the part about the accelerated tertiary stage. On the basis of the CDM model provided by Kowalewski [23], a new set of physically-based, unified uniaxial creep-aging constitutive model which can reflect the influences of different pre-stretching, stress levels and creep-aging system, have been innovatively introduced, these are mathematically expressed, as below,

$$
\begin{gathered}
\dot{\varepsilon}_{\mathcal{C}}=\alpha \sin h \cdot\left[\beta\left(\sigma-\sigma_{0}\right) \cdot(1-H)^{n_{0}} \cdot(1-G)^{m_{0}}\right] \cdot \exp (-Q / R T) \\
\dot{H}=\left(h / \sigma^{n_{1}}\right) \cdot\left(1-H / H^{*}\right) \cdot\left(1+G / G^{*}\right)^{m_{1}} \cdot \dot{\varepsilon}_{\mathcal{C}}
\end{gathered}
$$

where $\alpha, \beta, H^{*}, m_{0}, m_{1}, n_{0}, n_{1}$ and $h$ are material constants; $\dot{\varepsilon}_{c}$ describes creep strain rate of material; $R$ corresponds to universal gas constant; $Q$ and $T$ refer to apparent activation energy of creep and aging temperature, respectively. Among them, the range of $Q$ is evaluated to be 85.832 to $90.921 \mathrm{KJ} / \mathrm{mol} \mathrm{when}$ the variety of $\mathrm{n}_{1}$ is from 1.9 to 2.6 [24,25]; $G$ is the magnitude of real-time pre-stretching, corresponding to the current pre-stretching and $G^{*}$ refers to the magnitude of current maximum pre-stretching; $\sigma$ is the applied stress and $\sigma_{0}$ is the threshold stress that obstacle dislocation mobility.

\subsection{Description of State Control Variables}

In the current study, the mathematical formula in Equation (2) can be adopted to embody the enhancement effect of pre-stretching on the steady-creep rate at the second stage. $H^{*}$ is the saturation amount in dislocation strengthening and reflects the variation ratio of dislocation enhancement induced by the work-hardening, which mainly regulates the deformation rate of the primary creep stage. H can be described as the control amount affecting the trend of creep curve and is the bridge connecting the macroscopic deformation with the microstructure change. Under the constant stress of $\sigma$, the typical curve for $\mathrm{H}-\mathrm{t}$ is illustrated in Figure 8. It can be seen from the previous figure that $H$ increases with time and then eventually reaches a maximum and becomes near saturation amount, $H^{*}$. Combined 
with the Equation (2), it can be known that the increasing rate, $\dot{H}$, reaches the maximum when $H$ is zero and $\dot{H}$ tends to be zero when the $H$ infinitely approaches $H^{*}$ (seeing the dashed red line of Figure 8). But in a realistic calculation, $H$ will never reach the saturation state of $H^{*}$, as a result, the creep strain rate, $\dot{\varepsilon}_{\mathcal{C}}$, in Equation (1) can never be maintained at a constant second stage of creep. Therefore, based on the actual requirement in engineering application, the current paper regards $95 \% H^{*}$ (corresponding to aging time, $2.4 \mathrm{~h}$ ) as the starting point of steady creep, as shown by the dotted blue line in Figure 8 .

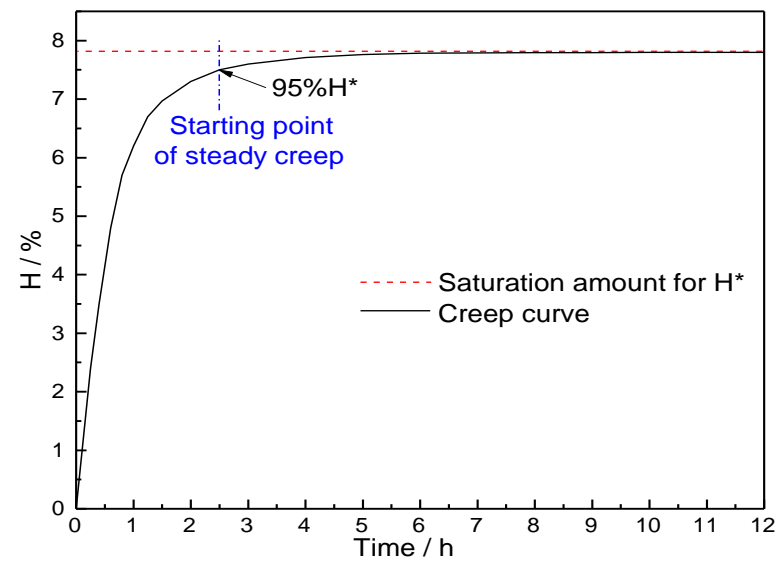

Figure 8. Typical creep curve showing the variety of $\mathrm{H}$ with time.

Meanwhile, for balancing both the inhibitory effect and the monotonicity capacity of pre-stretching at primary creep stage, Equation (1) describes the factors affecting pre-stretching. It can be obviously known that the factors affecting creep rate originates mainly from the struggle among $\left(\sigma-\sigma_{0}\right),(1-H)^{n 0}$ and $(1-G)^{m 0}$. For one thing, pre-stretching introduced before creep boosts the precipitation of the precipitated phase in the aluminum matrix (see Figure $6 c, d$ ) and further hinders the dislocation movements. So the values of $\left(\sigma-\sigma_{0}\right)$ and $(1-H)^{n 0}$ decrease as pre-stretching increases, and for another it is easier to obtain the strong movement of dislocations due to the continuous generation of dislocation slip and climb in alloy (see Figure 7). Thus, the magnitude of $\left(1+G / G^{*}\right)^{m 1}$ in Equation (2) improves the competition capacity of $(1-G)^{m 0}$ in Equation (1) with an increase in pre-stretching. In addition, $\alpha$ and $\beta$ in Equation (1) dominate the rate change in the steady creep stage. $m_{0}$ and $m_{1}$ reflect the influence of pre-stretching on different creep stages, respectively. $n_{0}$ and $n_{1}$ respectively show the diverse amount affecting the trend of creep curve and the state of current stress limited by the Peierls stress and the amount of nanoparticles [26].

\subsection{Determination of Material Constants for 7055-T6 Alloy}

Due to too many material constants needed to compute in the current constitutive equation, it is difficult to properly fit creep curves using the gradient-based optimization algorithm. With the above creep experiment data for studied 7055-T6 alloy, an advanced algorithm [27], i.e., Genetic Algorithm Optimization Toolbox (GAOT), is employed on MATLAB (Matlab2016a, MathWorks, Inc., Natick, MA, USA) platform to obtain exact constants that can describe the feature of creep and effect of pre-stretching on material, as listed in Table 2. Figure 9 shows the results between fitting predicted curves and experiment data. It can be seen clearly that the modified model couples with effects of pre-stretching, stress and creep-aging system have a good agreement with experiment data, and it can illustrate creep behaviors of the studied 7055-T6 alloy under different conditions very well. 
Table 2. Material constants in the creep constitutive equation for $7055-\mathrm{T} 6$ alloy at $155^{\circ} \mathrm{C}$.

\begin{tabular}{|c|c|c|c|c|c|}
\hline Parameters & Values & Parameters & Values & Parameters & Values \\
\hline$\alpha$ & 3.062 & $n_{0}$ & 1420 & $H^{*}$ & 0.237 \\
\hline$h$ & 216.473 & $m_{0}$ & 2.406 & $G^{*}$ & 0.214 \\
\hline$\beta$ & 0.108 & $\begin{array}{c}Q \\
(\mathrm{KJ} / \mathrm{mol})\end{array}$ & 88.351 & $m_{1}$ & 1.462 \\
\hline$\sigma_{0}(\mathrm{MPa})$ & 167,000 & $n_{1}$ & 2.038 & - & - \\
\hline
\end{tabular}
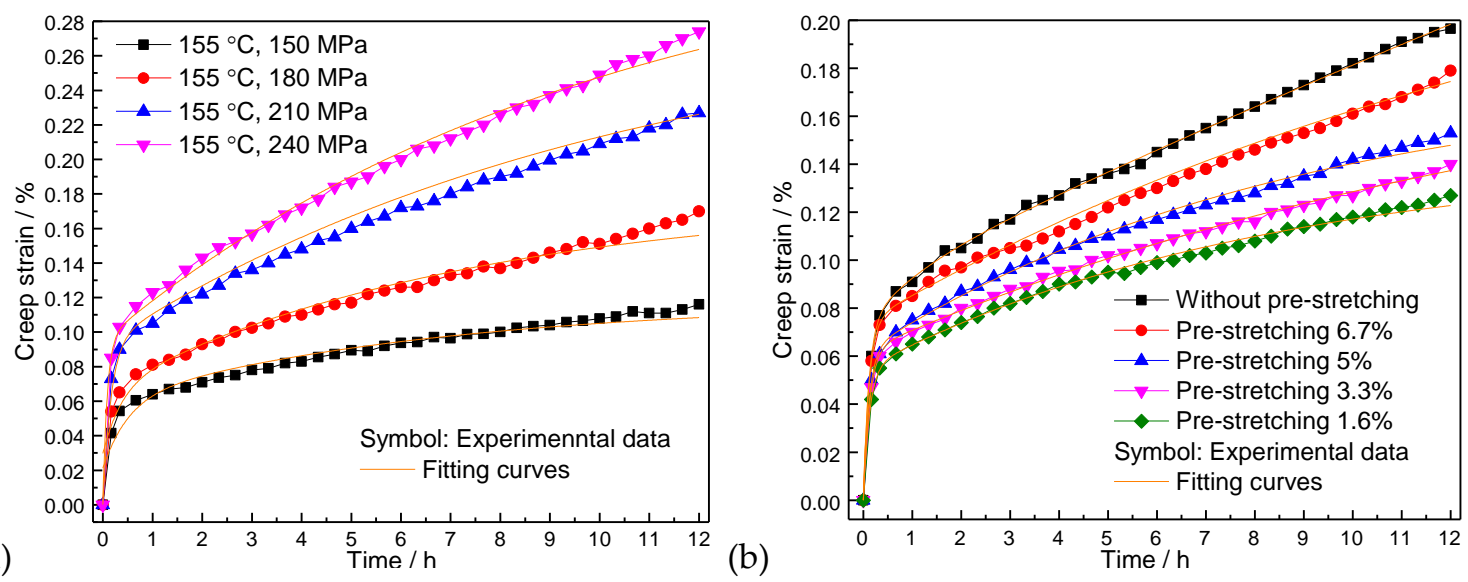

Figure 9. Comparison of experimental and predicted creep curves for 7055 alloy treated by (a) T6 under the same temperature, different stresses and without pre-stretching, and by (b) T6 under the same temperature, same stress and different pre-stretching values.

\section{Conclusions}

In this work, the effect of pre-stretching on mechanical behaviors and microstructures during creep-aging process of 7055 alloy was examined. Further, the tensile at ambient temperature and the creep tensile behavior at high temperature along with as-sociated changes in microstructures were analysed. A set of uniaxial creep-aging constitutive model was established to describe creep-aging behavior of pre-stretched 7055-T6. The important conclusions can be drawn:

(1) Comparing the creep behaviors of 7055 alloys between T6 state and solid solution state, it is obvious that the creep strain of the former after loading with short duration of primary creep, is better accelerated and more generated, and the T6-treated alloys have greater creep strain and more positive creep effect than the latter. Thus, the 7055 alloy in T6 state is a more beneficial scheme to obtain more creep strain without reducing its mechanical properties.

(2) The introduced pre-stretching can obviously improve the strengths of creep-aged 7055-T6 alloys, whose strengths are higher than that of un-creep-aged 7055-T6 alloy and show a tendency to slow increase at first and then quick decrease with the increase of pre-stretching. The range of pre-stretching from $1.6 \%$ to $3.3 \%$ is suitable for creep-aged alloy to obtain better mechanical properties.

(3) When comparing the creep results of 7055-T6 alloys between pre- and un-stretching, the total creep strain of non-stretched specimen originates from the primary creep stage and exceeds by $70 \%$. The pre-stretched alloys obviously shorten the duration of this stage and indirectly enhance the creep rate in steady-state creep stage. The larger pre-stretching will promote the positive effects on creep behaviors, resulting in the generation of more creep strain.

(4) A number of dislocations generated by pre-stretching provide superior nucleation regions for $\eta$ phase. Subsequently, the density of $\eta$ phases is high, the dislocations are more, and these will promote positive effects on creep behaviors, resulting in being fine in 7055-T6 alloy. With the increase in pre-stretching amount, the precipitation abilities of $\eta$ phase are gradually weakened due to the formation of greater and coarser $\eta$ equilibrium phases in grains, resulting in worse strength in 7055-T6 alloy. 
(5) The modified creep-aging constitutive model has a good agreement with the experimental data, which can be used to predict the creep-aging behavior of 7055-T6 alloy under the different pre-stretching and stress levels, as shown in formulas (1) and (2).

Author Contributions: conceptualization, D.Z. and Z.C.; methodology, D.Z.; software, Y.C.; validation, G.Z.; formal analysis, D.Z. and Z.C.; investigation, D.Z. and Z.C.; resources, D.Z.; data curation, Y.C. and G.Z.; writing—original draft preparation, D.Z.; writing—review and editing, D.Z., Z.C. and Y.C.; visualization, D.Z. and Z.C.; supervision, Z.C.; project administration, D.Z.; funding acquisition, D.Z.

Funding: This research was funded by Chongqing Engineering Technology Research Center for Light Alloy Materials and Processing, grant number GCZX201705 and The 2019yjzx0101 was funded by Chongqing Engineering Research Center for Advanced Intelligent Manufacturing Technology.

Acknowledgments: This research was supported by Chongqing Engineering Technology Research Center for Light Alloy Materials and Processing under contract GCZX201705, the Manufacturing Laboratory of Lightweighting Component, Department of Chong Three gorges University, C.H.N, and by Chongqing Engineering Research Center for Advanced Intelligent Manufacturing Technology under contract 2019yjzx0101, Research Department of Chongqing, C.H.N. The experiment was developed by Analytical and Testing Center (ATC), which is managed by Northwestern Polytechnic University, C.H.N. The authors are grateful to Laboratory Technician Liu H for a principle analysis and technical support on preparation of TEM samples.

Conflicts of Interest: The authors declare no conflict of interest.

\section{References}

1. Yan, L.M.; Shen, J.; Li, Z.B.; Li, J.P. Effect of deformation temperature on microstructure and mechanical properties of 7055 aluminum alloy after heat treatment. Trans. Nonferrous Met. Soc. China 2013, 23, 625-630. [CrossRef]

2. Schreiber, J.M.; Omcikus, Z.R.; Eden, T.J.; Sharma, M.M.; Champagne, V.; Patankar, S.N. Combined effect of hot extrusion and heat treatment on the mechanical behavior of 7055 AA processed via spray metal forming. J. Alloy. Compd. 2014, 617, 135-139. [CrossRef]

3. Rodgers, B.I.; Cinderey, R.J.; Prangnell, P.B. The influence of extended and variable pre-Stretching on the strength of AA2195 alloy taper-rolled plates. Mater. Sci. Forum 2016, 877, 205-210. [CrossRef]

4. Cao, C.; Zhang, D.; Zhuang, L.Z.; Zhang, J.S. Improved age-hardening response and altered precipitation behavior of Al-5.2Mg-0.45Cu-2.0Zn (wt\%) alloy with pre-aging treatment. J. Alloy. Compd. 2017, 691, 40-43. [CrossRef]

5. Zhan, L.H.; Ma, Z.Y.; Zhang, J.; Tan, J.S.; Yang, Z.; Heng, L. Stress relaxation ageing behaviour and constitutive modelling of a 2219 aluminium alloy under the effect of an electric pulse. J. Alloy. Compd. 2016, 679, 316-323. [CrossRef]

6. Lin, Y.C.; Zhang, J.L.; Liu, G.; Liang, Y.J. Effects of pre-treatments on aging precipitates and corrosion resistance of a creep-aged Al-Zn-Mg-Cu alloy. Mater. Des. 2015, 83, 866-875. [CrossRef]

7. He, Y.S.; Chang, J.C.; Lee, J.Y.; Shin, K.S. Effect of aging on the creep properties and microstructural evolution of P92 steel. Key Eng. Mater. 2017, 727, 52-58. [CrossRef]

8. Lin, J.; Ho, K.C.; Dean, T.A. An integrated process for modelling of precipitation hardening and springback in creep age-forming. Int. J. Mach. Tool. Manuf. 2006, 46, 1266-1270. [CrossRef]

9. Mehmanparast, A.; Davies, C.M.; Dean, D.W.; Nikbin, K. Effects of plastic pre-straining level on the creep deformation, crack initiation and growth behavior of $316 \mathrm{H}$ stainless steel. Int. J. Press. Vessel. Pip. 2016, 141, 1-10. [CrossRef]

10. Yang, Y.L.; Zhan, L.H.; Ma, Q.Q.; Feng, J.W.; Li, X.M. Effect of pre-deformation on creep age forming of AA2219 plate: Springback, microstructures and mechanical properties. J. Mater. Process. Technol. 2016, 229, 697-702. [CrossRef]

11. Zuo, X.J.; Li, J.C.; Liu, D.H.; Zheng, L.F. Establishment of an ANSYS-based constitutive modeling for age forming of aluminum alloy. Appl. Mech. Mater. 2012, 217-219, 1497-1500. [CrossRef]

12. Zuo, D.Q.; Ma, G.L.; Deng, Z.H.; Luo, J.J.; Wang, H.B. Research on the improved Graham model for aluminum-based alloy stiffened panel under the whole creep aging process. Chin. J. Appl. Mech. 2018, 35, 894-899. 
13. Li, Y.; Shi, Z.; Lin, J.; Yang, Y.L.; Huang, B.M.; Chung, T.F.; Yang, J.R. Experimental investigation of tension and compression creep-ageing behaviour of AA2050 with different initial tempers. Mat. Sci. Eng. A 2016, 657, 299-308. [CrossRef]

14. Liu, S.D.; Wang, S.L.; Ye, L.Y.; Deng, Y.L.; Zhang, X.M. Flow behavior and microstructure evolution of 7055 aluminum alloy impacted at high strain rates. Mater. Sci. Eng. A 2016, 667, 203-210. [CrossRef]

15. Rodgers, B.I.; Prangnell, P.B. Quantification of the influence of increased pre-stretching on microstructure strength relationships in the Al-Cu-Li alloy AA2195. Acta Mater. 2016, 108, 55-67. [CrossRef]

16. Cassada, W.A.; Shiflet, G.J.; Starke, E. The effect of plastic deformation on Al 2 CuLi (T1) precipitation, Metall. Mater. Trans. A 1991, 22, 299-306. [CrossRef]

17. Zuo, J.R.; Hou, L.G.; Shi, J.T.; Cui, H.; Zhuang, L.Z.; Zhang, J.S. The mechanism of grain refinement and plasticity enhancement by an improved thermo-mechanical treatment of $7055 \mathrm{Al}$ alloy. Mater. Sci. Eng. A 2017, 702, 42-53. [CrossRef]

18. Zuo, J.R.; Hou, L.G.; Shi, J.T.; Cui, H.; Zhuang, L.Z.; Zhang, J.S. Effect of deformation induced precipitation on grain refinement and improvement of mechanical properties AA 7055 aluminum alloy. Mater. Charact. 2017, 130, 123-134. [CrossRef]

19. Wang, T.; Yin, Z.M.; Shen, K.; Li, J.; Huang, J.W. Single-aging characteristics of 7055 aluminum alloy. Trans. Nonferrous Met. Soc. China 2007, 17, 548-552. [CrossRef]

20. Mondal, C.; Mukhopadhyay, A.K.; Raghu, T.; Varma, V.K. Tensile properties of peak aged 7055 aluminum alloy extrusions. Mat. Sci. Eng. A 2007, 454-455, 673-678. [CrossRef]

21. Lei, C.; Li, H.; Zheng, G.W.; Fu, J. Thermal-mechanical loading sequences related creep aging behaviors of 7050 aluminum alloy. J. Alloy. Compd. 2018, 731, 90-99. [CrossRef]

22. Yang, Y.L.; Zhan, L.H.; Shen, R.L.; Yin, X.N.; Li, X.C.; Li, W.K.; Huang, M.H.; He, D.Q. Effect of pre-deformation on creep age forming of 2219 aluminum alloy: Experimental and constitutive modeling. Mat. Sci. Eng. A 2017, 683, 227-235. [CrossRef]

23. Kowalewski, Z.L.; Hayhurst, D.R.; Dyson, B.F. Mechanism-based creep constitutive equations for an aluminum alloy. J. Strain Anal. Eng. Des. 1994, 29, 309-316. [CrossRef]

24. Mirzadeh, H. Constitutive description of 7075 aluminum alloy during hot deformation by apparent and physically-based approaches. J. Mater. Eng. Perform. 2015, 24, 1095-1099. [CrossRef]

25. Sket, F.; Dzieciol, K.; Isaac, A.; Borbély, A.; Pyzalla, A.R. Tomographic method for evaluation of apparent activation energy of steady-state creep. Mater. Sci. Eng. A 2010, 527, 2112-2120. [CrossRef]

26. Li, Y.; Langdon, T.G. A unified interpretation of threshold stresses in the creep and high strain rate superplasticity of metal matrix composites. Acta Mater. 1999, 47, 3395-3403. [CrossRef]

27. Zheng, J.H.; Lin, J.G.; Lee, J.Y.; Pan, R.; Li, C.; Davies, C.M. A novel constitutive model for multi-step stress relaxation ageing of a pre-strained 7xxx series alloy. Int. J. Plast. 2018, 106, 31-47. [CrossRef] 